\title{
MECHANISM OF ADSORPTION AND ELECTROSORPTION OF BENTAZONE ON ACTIVATED CARBON CLOTH IN AQUEOUS SOLUTIONS
}

\author{
Conchi O. Ania, François Béguin* \\ CRMD, CNRS-University, 1B rue de la Férollerie, 45071 Orléans, France \\ * Corresponding author: \\ F. Béguin, CRMD, CNRS-University, 1B rue de la Férollerie, 45071 Orléans, France \\ E-mail: beguin@cnrs-orleans.fr
}

\begin{abstract}
An electrochemical technique has been applied to enhance the removal of a common herbicide (bentazone) from aqueous solutions using an activated carbon cloth as electrode. A $\mathrm{pH}$ increase from acidic to basic reduces the uptake, with capacities going from 127 down to $80 \mathrm{mg} / \mathrm{g}$ at $\mathrm{pH} 2$ and 7, respectively. Increasing the oxygen content of the carbon cloth causes a decrease in the bentazone loading capacity at all $\mathrm{pH}$ values. This indicates that adsorption is governed by both dispersive and electrostatic interactions, the extent of which is controlled by the solution $\mathrm{pH}$ and the nature of the adsorbent. Anodic polarization of the carbon cloth noticeably enhances the adsorption of bentazone, to an extent depending on the current applied to the carbon electrode. The electrosorption is promoted by a local $\mathrm{pH}$ decrease provoked by anodic decomposition of water in the pores of the carbon cloth. Keywords: electrosorption, pesticides, activated carbon cloth
\end{abstract}




\section{Introduction}

Lately, there has been an increasing trend in the total volume of sales of agricultural pesticides, being herbicides one of the biggest groups used in the European Union (EU). Their repetitive utilization to maintain health crops has lead to an increase of their level in wastewater from industrial and human activities. Moreover, pesticides are considered by the EU as priority pollutants (Directive 2000/60/EC) as they are highly noxious, long-term persistent and highly mobile throughout the environment, and most of them also present carcinogenic properties. Therefore, the issue of their removal has become a field of growing interest. Pesticides are commonly present in low concentrations, and seldom exceed water-quality standards. However, high concentrations can appear in surface water during runoff in agricultural areas soon after pesticide application to the farm field, and in water from urban basins as a consequence of urban development and abusive household uses.

Intensive interest has arisen in recent years on the development of procedures for the purification of wastewater. Among the conventional methods, biological treatment is by far the most widely applied and a cost effective one. Unfortunately this alternative cannot deal with the non-biodegradable organic compounds (aromatics, polycylic aromatic hydrocarbons, pesticides) present in wastewater, which in addition are very often inhibitors of the biological processes. These compounds have to be eliminated by high cost and irreversible methods, which make the whole process not affordable from an economical point of view. Reverse osmosis, ion-exchange resins and adsorption on activated carbons are among the most utilized (Karanfil, 2006; Pintar, 2005; Hinkebeina and Price, 2005). Their major drawbacks are a poor economic feasibility, a limited applicability and effectiveness, and a short lifetime due to low regeneration capacities. 
On the other hand, electrosorptive techniques employing high surface area electrodes of nano-textured materials (such as activated carbons) have been developed as a potential technology for removing toxic pollutants from aqueous solutions (Oren and Soffer, 1983; Alfarra et al., 2002; Niu and Conway, 2002a-c; Niu and Conway, 2003; Matlosz and Newman, 1986; Ying et al., 2002; Afkhami and Conway, 2002; Ayranci and Conway, 2001; Han et al., 2006a,b). The working principle of electrosorption is based on imposing an external electric field in order to force charged species such as ions to move toward oppositely charged electrodes.

Until now, extensive research has been carried out on the electrosorption of toxic inorganic ions (Oren and Soffer, 1983; Alfarra et al., 2002; Matlosz and Newman, 1986; Ying et al., 2002; Afkhami and Conway, 2002) and a few organic molecules -i.e., phenol and aniline(Niu and Conway, 2002a-c; Niu and Conway, 2003; Ayranci and Conway, 2001; Han et al., 2006a,b). Although the results have shown good efficiency of ions removal, and that polarization of the carbon surface in a suitable electrolyte could, to some extent, improve the adsorption of some organic pollutants, scarce works report the application of this technique to the removal of pesticides or more complicated polycyclic aromatic compounds (Niu and Conway, 2002a-c; Niu and Conway, 2003; Ban et al., 1998). In this regard, the adsorption of pesticides constitutes an interesting field of research due to their increasing use in both industrial and domestic applications. Particularly, the use of bentazone, a postemergence herbicide, has become very popular for the control of broad-leaved weeds and crops since 2003 after the ban of atrazine in the EU. In association, the herbicides alachlor and bentazone can be substituted for atrazine to provide the same spectrum of action on weds in cereals grains crops (mainly maize and rice), resulting in new environmental risks (Dousset et al., 2004). Moreover, this herbicide has a relatively high mobility in water. So 
far, bentazone adsorption has been reported on carbon materials, although neither the use of electrochemical techniques, nor the effects of the adsorbent properties on the overall adsorption capacity have been yet explored (Ayranci and Hoda, 2004).

The main objective of this research is to explore the application of electrosorptive techniques for the removal of bentazone, using activated carbon cloth as electrode. The efficiency of the electrosorption process was carefully investigated. Special attention was paid to the many factors (heterogeneity of the carbon surface, solution $\mathrm{pH}$, current) that affect the complex process of adsorption and electrosorption from diluted solutions.

\section{Materials and methods}

\subsection{Materials}

A commercial activated carbon cloth $-A X$-, obtained from physical activation of rayon and supplied by ACTITEX (France) was chosen for this study. Before usage, $A X$ was washed with distilled water at $60{ }^{\circ} \mathrm{C}$ during one week. Then, it was dried at $80{ }^{\circ} \mathrm{C}$ overnight and stored in a dessicator until use. In order to modify the surface chemistry, the carbon cloth was oxidized with ammonium persulfate in water solution as described elsewhere (Ania et al, 2004). After oxidation, the sample was washed and dried at $110^{\circ} \mathrm{C}$ overnight; it will be labeled as AXO. Bentazone [3-Isopropyl-1H-2,1,3-benzothiadiazin-4(3H)-one-2, 2dioxide]- with the highest purity specification was obtained from Aldrich. For clarity, the molecular structure of bentazone is shown in Figure 1.

\subsection{Equilibrium adsorption isotherms in open-circuit (OC)}

Adsorption of bentazone from aqueous solutions was measured at room temperature in a stirred batch system. Kinetic studies revealed that the adsorption equilibrium was established after 3 days. Details of the procedure followed for the measurement of the 
adsorption isotherms are described elsewhere (Ania et al., 2004). Briefly, different amounts of carbons (from $5 \mathrm{mg}$ to $100 \mathrm{mg}$ ) were weighed and added to flasks containing $0.05 \mathrm{~L}$ of a bentazone solution of concentration $20 \mathrm{mg} \mathrm{L}^{-1}$, and shaken for $72 \mathrm{~h}$. Equilibrium concentrations of the solutions were measured using a UV spectrometer (Uvikon Xs, BioTEk Instruments) at the corresponding maximum absorption wavelength depending on the solution $\mathrm{pH}$. The equilibrium data were fitted to the so-called Langmuir-Freundlich (LF) single solute isotherm (Derylo-Marczewska et al., 1984), which has the equation:

$\vartheta_{t}=\frac{q_{e}}{q_{o}}=\frac{(K C)^{n}}{1+(K C)^{n}}$

where $q_{e}$ is the adsorbed amount of solute per unit gram of adsorbent, $q_{o}$ is its maximum adsorption per unit mass of the adsorbent, $K$ is the Langmuir-type constant defined by the van't Hoff equation, and the exponential term $n$ represents the heterogeneity parameter. The effect of solution $\mathrm{pH}$ on adsorption in $\mathrm{OC}$ was investigated using $\mathrm{HCl} / \mathrm{KCl} 0.1 \mathrm{M}(\mathrm{pH} 2)$ and phosphate ( $\mathrm{pH} 7)$ buffers.

\subsection{Kinetics of adsorption / electrosorption}

Kinetics of adsorption/electrosorption were determined in $20 \mathrm{ml}$ of bentazone aqueous solution (initial concentration $20 \mathrm{ppmw}$ ) with a fixed adsorbent mass $(11 \pm 0.5 \mathrm{mg})$. However, due to the low electrical conductivity of the pesticide solutions, $0.01 \mathrm{~mol} . \mathrm{L}^{-1}$ $\mathrm{Na}_{2} \mathrm{SO}_{4}$ (having a $\mathrm{pH}$ around 5-6) was used as inert supporting electrolyte for the electrosorption experiments. The carbon cloth was cut in desired dimensions, weighed accurately, and attached to a gold disk used as current collector, this acting as working electrode. A platinum grid served as an auxiliary electrode and $\mathrm{Hg} / \mathrm{Hg}_{2} \mathrm{SO}_{4}$ as reference electrode. Small samples of the solution $(2 \mathrm{~mL})$ were taken out at predetermined time 
intervals to measure the $\mathrm{pH}$ evolution and the concentration of the pollutant during sorption, using UV spectrophotometry. This procedure enabled to investigate kinetics of adsorption under both open-circuit (OC) and polarization at different current values of $+1,+2$ and $+5 \mathrm{~mA}$ (i.e., galvanostatic mode). The adsorption rate constants were determined from the first-order adsorption kinetics equation,

$\log \left(q_{e}-q\right)=\log q_{e}-\frac{K_{a d s} t}{2.303}$

where $K_{\text {ads }}\left(\mathrm{min}^{-1}\right)$ is the adsorption rate constant and $q_{e}$ and $q$ are the amounts of bentazone adsorbed $\left(\mathrm{mg} \mathrm{g}^{-1}\right)$ at equilibrium and time $\mathrm{t}(\mathrm{min})$, respectively.

\subsection{Textural and chemical characterization of the carbon cloths}

Nanotexture of the carbon cloths was characterized by $\mathrm{N}_{2}$ adsorption at $-196^{\circ} \mathrm{C}$ (Autosorb-1, Quantachrome). Before the experiments, the samples were outgassed under vacuum at $120^{\circ} \mathrm{C}$ overnight. The isotherms were used to calculate the specific surface area, $\mathrm{S}_{\mathrm{BET}}$, total pore volume, $\mathrm{V}_{\mathrm{T}}$, and pore size distribution using the density functional theory (DFT). Additionally, the distribution of pores smaller than $0.7 \mathrm{~nm}$ (narrow micropores) was assessed from $\mathrm{CO}_{2}$ adsorption isotherms at $0{ }^{\circ} \mathrm{C}$ with $\mathrm{DR}$ formulism. The different types of surface functional groups were identified by X ray photoelectron spectroscopy (XPS) using an Escalab MK2 (VG Instrument) equipped with an X-ray aluminum source ( $\mathrm{K}_{\alpha}$ radiation). The materials were further characterized by the determination of the point of zero charge ( $\mathrm{pH}_{\mathrm{PZC}}$ ) by mass-titration as described elsewhere (Noh and Schwarz, 1989).

\section{Results and discussion}

\subsection{Characterization of the carbon cloths}


Nanotextural data of the $A X$ and $A X O$ cloths are presented in Table 1. In both cases the nitrogen adsorption isotherms belong to type $I$ in the BDDT (Brunauer-Deming-Deming-Teller) classification (Brunauer et al., 1940), which indicates that the carbons are mainly microporous, even after modification. The oxidized sample AXO shows minor changes in the pore volumes, as compared to the initial counterpart. This affects mainly the pores of larger size (mesopores), as evidenced by the pore size distribution (PSD) evaluated by the DFT method. An exhaustive analysis of the PSD combining the information of $\mathrm{N}_{2}$ and $\mathrm{CO}_{2}$ adsorption isotherms also corroborates this fact, as the narrow microporosity evaluated from the $\mathrm{CO}_{2}$ data remains almost constant in both cloths. It can be inferred from these results that the carbon cloth modification turns out in almost negligible alterations in microporosity, and a slight increase in mesopore volume.

The nature of the functionalities created on the carbon surface after the oxidation with ammonium persulfate was studied by XPS (Table 1). It can be seen that oxidation turns out in a three-fold increase of oxygen amount in the $A X O$ sample. Mainly quinone-like and carboxylic groups were introduced on the carbon matrix after oxidation. As expected, the oxidized sample becomes more acidic $\left(\mathrm{pH}_{\mathrm{PZC}}=2.5\right)$ confirming that the majority of the functionalities created are of an acidic nature. The presence of oxygen functionalities was also confirmed by the electrochemical characterization of the carbon materials by cyclic voltammetry in 1 mol.L $\mathrm{L}^{-1} \mathrm{H}_{2} \mathrm{SO}_{4}$. In the case of the AXO sample, a reversible hump appeared in the voltammogram, due to redox transfer transitions involving proton exchange between the electrolytic medium and the oxygen-containing functionalities incorporated to the carbon matrix. The position of the cathodic and anodic peaks confirms the existence of the quinone/hydroquinone pair (reduction potential close to $-0.15 \mathrm{~V}$ vs. $\mathrm{Hg} / \mathrm{Hg}_{2} \mathrm{SO}_{4}$ for carbons (Kinoshita, 1988) in various environments. 
On the basis of these results, it can be concluded that the porous features of the cloth were not much altered upon oxidation in mild conditions. Hence, it is possible to modify the surface functionality of an activated carbon without changing considerably the porous texture. In this way, a proper understanding of the role of activated carbon surface functionality in the retention of toxic pollutants from aqueous medium at low concentration can be acquired.

\subsection{Adsorption of bentazone at open-circuit (OC)}

Adsorption kinetics must be investigated in order to determine the time necessary for reaching equilibrium, and to elucidate the mechanism of the adsorption process. The rate of bentazone adsorption on both carbons was compared at different $\mathrm{pH}$ values by measuring the variation of concentration as a function of time, using solutions of equal volume and initial concentration and carbon-cloth pieces of equal mass. In all cases, the experimental data were fitted by a pseudo-first-order kinetics, with correlation coefficients higher than 0.98 (Table 2). This result is in good agreement with those reported by Ayranci et al. on a carbon adsorbent with more developed porosity (Ayranci and Hoda, 2004).

Figure 2 shows different adsorption behaviors, being the adsorption rate much faster for the non oxidized carbon cloth $-A X-$, and also in acidic medium, the later being more significant in the AXO sample. Consequently, surface functionalities of acidic nature have a negative effect on the overall adsorption rate, whereas regarding the solution $\mathrm{pH}$, the adsorption proceeds faster in acidic medium in both carbons, suggesting an effect of electrostatic interactions. The different adsorption rates might be explained in terms of the pesticide structure and/or surface functionality of the carbon cloths. This issue will be more extensively discussed later. 
For the purpose of understanding the role of different surface heterogeneities on the mechanism of bentazone adsorption, the adsorption under equilibrium conditions was evaluated. The experiments showed that the pesticide concentration remains unchanged after $24-48 \mathrm{~h}$ contact with the carbon cloth. Therefore, a contact time of $48 \mathrm{~h}$ was selected for evaluating the adsorption isotherms at open-circuit (OC). The obtained isotherms at different $\mathrm{pH}$ values are shown in Figure 3. Their shape indicates that they belong to the Ltype in the Giles classification (Giles et al., 1960), which suggests that bentazone is preferentially adsorbed than the solvent (water) on the carbon substrate. In most cases, the adsorption isotherms show a tendency to reach a plateau at a high equilibrium concentration of bentazone (i.e., low dose of adsorbent) indicating that the saturation limit is attained. Following the same trend obtained for kinetics measurements, the adsorption capacity decreases promptly after oxidation, regardless the solution $\mathrm{pH}$; the adsorption capacity is higher in those activated carbons with a low concentration of surface oxygen groups, i.e., the AX sample.

The adsorptive capacity of the carbons was obtained after fitting the experimental data by the Langmuir-Freundlich (LF) model. The results are shown in Table 3, along with the parameters of surface heterogeneity and the correlation coefficient. According to the results observed, the adsorption capacity decreases drastically in the oxidized carbon, regardless the solution $\mathrm{pH}$, although this effect is more remarkable with increasing $\mathrm{pH}$. Since the analysis of the textural properties of the carbons after oxidation revealed very small changes in the porous network, this behavior is certainly linked to the functionalities created on the carbon surface. Moreover, for a given cloth, the uptake is larger under acidic $\mathrm{pH}$ conditions (Table 3), where the neutral form of bentazone is predominant in solution, suggesting that bentazone is preferentially adsorbed in a molecular form. 
Due to the complex structure of bentazone (Figure 1), several adsorptive forces may occur simultaneously. Given the aromatic structure, dispersion forces should be expected between the $\pi$ electron density of the graphene layers on the carbon cloth and the aromatic ring of the adsorbate. Also, some specific localized interactions might arise from the polar groups (i.e., sulfoxide and carbonyl- type). The decrease of adsorption rate observed after oxidation is most probably due to the alteration of the $\pi$ electronic density on the carbon surface as a result of its functionalization. It is well-known that the oxygen functionalities are mainly located at the edges of the basal planes and the entrance of the pores in activated carbons (Donnet, 1982). Taking this into account and being the majority of surface groups of electron-acceptor character (Table 1), functionalization of the carbon cloth withdraws $\pi$ electrons from the graphene layers, and then the contribution of dispersive interactions to adsorption is lessened.

Competitive adsorption of water molecules must also be considered, since the carbon cloth becomes more hydrophilic upon oxidation. The oxygen groups are ideal sites for water adsorption, favoring the creation of water clusters at the entrance of the pores. Those hydration clusters might effectively reduce and/or hinder the accessibility and affinity of a polyaromatic molecule as bentazone to the inner porous texture (Franz et al., 2000) of the carbon. This would also explain the slower adsorption rate of $A X O$ vs the $A X$ sample. Hence, the surface is more densely populated by bentazone molecules for carbon materials with the smallest oxygen content and the largest regions of high $\pi$-electron density.

As for the effect of the solution $\mathrm{pH}$, loading capacities increased at acidic $\mathrm{pH}$ in both carbons. Therefore, it seems reasonable to link such a behavior with two factors: the ionization of the adsorbate and the charges on the carbon surface. The possible interactions 
between the carbon cloth and bentazone would be either dispersive interactions between the aromatic ring and the $\pi$ electrons of the graphitic structure, or electrostatic attraction/repulsion when ions are present.

On the first hand, $\mathrm{pH}$ changes affect the dissociation of the bentazone molecule. Bentazone is a weak acid with a $\mathrm{pK}_{\mathrm{a}}$ of 3.3 ; thus, it exists predominantly in anionic form under $\mathrm{pH}$ conditions near neutrality. According to the dissociation constant, the neutral molecule is the main structure in solution at $\mathrm{pH} 2$ accounting for $95 \mathrm{~mol} \%$. By contrast, the conversion of bentazone to its anionic form starts to be important in the $\mathrm{pH}$ range of 4-6. At $\mathrm{pH} 4$ the anionic form accounts for $83 \mathrm{~mol} \%$ and at $\mathrm{pH}$ 6-7 it represents more than $99 \mathrm{~mol} \%$. The decrease of amount adsorbed at higher $\mathrm{pH}$ (anionic form predominant in solution) suggests a weaker interaction of the carbon surface with deprotonated (anionic) bentazone than with its neutral form, and consequently that the adsorption is dominated by dispersive interactions between the pesticide and the adsorbent surface. Similar results on the $\mathrm{pH}$ dependence of bentazone adsorption on soils and clays have been reported (Boivin et al., 2004; Boivin et al., 2005; Grey et al., 1996).

On the other hand, $\mathrm{pH}$ changes also affect the adsorptive process through functional groups dissociation on the adsorbent surface; the carbon surface may be either positively or negatively charged depending on the nature of the carbon cloth. At a given $\mathrm{pH}$, the carbon surface and the adsorbate species may coexist in a complex system, in which the same or opposite charges maybe present, resulting in some widely different adsorption schemes. When adsorption occurs from the un-buffered solution $(\mathrm{pH} 5.5)$ or at $\mathrm{pH} 7$, bentazone ionization is dominant $\left(\mathrm{pH}>>\mathrm{pK}_{\mathrm{a}}\right)$ and additionally negatively charged surface sites exist on the carbon surface $\left(\mathrm{pH} />\mathrm{pH}_{\mathrm{PZC}}\right)$. Therefore the adsorption capacity is drastically 
reduced since negative charges along the edges of the graphitic layers repel the bentazone anions, thereby reducing access of ions to the graphene surface (reducing dispersive interactions). At acidic $\mathrm{pH}$ in contrast, the negative charges at the edge of graphene layers are neutralized (all acidic groups are protonated and bentazone is mainly non-dissociated); thus repulsive electrostatic interactions are minimized and adsorption is enhanced. This effect is more remarkable in the AXO sample.

\subsection{Adsorption of bentazone under polarization}

To ensure that bentazone is not oxidized or reduced during the electrosorption process, the electrochemical stability of the pesticide was investigated. Cyclic voltammograms of the aqueous 0.01 mol.L $\mathrm{L}^{-1} \mathrm{Na}_{2} \mathrm{SO}_{4}$ solution, with and without the targeted pollutant, were recorded at a scan rate of $20 \mathrm{mVs}^{-1}$ in the potential range between -0.85 and $+1.25 \mathrm{~V}$ vs $\mathrm{Hg} / \mathrm{Hg}_{2} \mathrm{SO}_{4}$. No differences were found in the cyclic voltammograms when the herbicide is present in the solution; this was confirmed by monitoring the UV absorption spectra, which indicated that bentazone is stable in this potential range.

Anodic polarization (positive) was applied to the carbon cloth at constant current (i.e., galvanostatic conditions) in the un-buffered solution, which resulted in an enhancement of the adsorption rate, as it can be seen in Figure 4. Increasing the anodic current from $+1 \mathrm{~mA}$ to $+5 \mathrm{~mA}$ substantially improved the adsorption rate, as it can also be seen from the parameters of first-order kinetics (Table 2). Figure 5 shows that positive polarization causes a rise of electrode potential, the latter being more important with increasing the applied current. The electrode potential reaches values that enable the electrolyte decomposition at the working electrode according to:

$$
2 \mathrm{H}_{2} \mathrm{O} \rightarrow \mathrm{O}_{2}+4 \mathrm{H}^{+}+4 \mathrm{e}^{-}
$$


The generation of protons in the pores of the working electrode gives rise to a local $\mathrm{pH}$ decrease, which we believe should be responsible for the improved adsorption rate, given that the ionization of bentazone and the charge of the carbon surface functionalities are being altered. This generation of protons causes the protonation of the anionic bentazone form (predominant in un-buffered solution, as stated above) to the neutral form, thus enhancing the adsorption rate, which confirms the trend observed in OC.

It should also be mentioned that, due to oxygen evolution, a slight functionalization of the carbon cloth might occur. Oxidation can also cause a collapse of the porous texture of the carbon cloth, particularly if it is carried out under sever conditions (Harry et al., 2007; Park and Kim, 2004). In this study, the mild experimental conditions of the electrochemical treatment (current up to $+5 \mathrm{~mA}$ during 3 hours) prevented a large deterioration of the porous texture of the $\mathrm{AX}$ carbon cloth, with a $12 \%$ decrease in the micropore volume evaluated by $\mathrm{CO}_{2}$ adsorption (after anodic oxidation in the absence of the adsorbate, to eliminate any effect due to adsorption). Based on the mechanism proposed for adsorption under OC conditions, modification of surface functionality could have a negative effect on bentazone uptake. Since it is not the case, one has to conclude that oxygen evolution produces either acidic groups in small amount or surface groups which dissociation is not $\mathrm{pH}$ dependent.

Therefore it is reasonable to presume that bentazone is electrosorbed via $\pi-\pi$ dispersive interactions with the aromatic ring approaching to the carbon surface (Figure 6). Attractive electrostatic interactions between the anionic form of bentazone (if still remaining in the solution) and the positively charged carbon surface (induced by the anodic polarization) might also occur to some extent (Figure 6). A similar mechanism and orientation has been 
proposed for electrochemical enhanced adsorption of aniline on activated carbon fibers (Han et al., 2006), with electrosorption taking place through the aromatic ring approaching the charged carbon surface. Hence, in non buffered $\mathrm{Na}_{2} \mathrm{SO}_{4}$, it might be concluded that the pesticide shifted to its neutral form due to local $\mathrm{pH}$ changes in the pores of the carbon electrode, becoming adsorbed on the carbon cloth to a larger rate, as evidenced by the kinetics and equilibrium adsorption isotherms in OC.

It is interesting to point out that the passage of charge in the non-buffered solution gave rise to a slight $\mathrm{pH}$ increase (up to one unit increase). This is linked to the faradaic production of $\mathrm{OH}^{-}$ions at the counter electrode during polarization. Although the $\mathrm{OH}^{-}$ions created should be neutralized by the $\mathrm{H}^{+}$liberated at the working electrode, in this case the $\mathrm{pH}$ balance does not apply because the anodic process includes the non-faradaic charging (electrical double layer) of the high surface area carbon cloth. This behavior has also been reported for the electrosorption of azine-type pollutants (Niu and Conway, 2002a). Although the increase is small, this might appreciably affect the efficiency of the electroadsorptive removal of the pollutant. In other words, the generation of protons at the working electrode seems to be critical for the enhancement of the electrosorption.

Keeping in mind the seek of possible applications of these electrosorption properties, in situ absorption spectra of the bentazone solution were recorded upon anodic polarization. The absence of line shift while polarization is applied (Figure 7) confirms the structural integrity of bentazone even at the high cell potentials reached during the electrosorption experiments.

To summarize, it seems that local $\mathrm{pH}$ is the main factor which controls the adsorption and electrosorption of bentazone, and that bentazone is mainly trapped via $\pi-\pi$ dispersive 
interactions with the aromatic ring approaching to the carbon surface. To corroborate this mechanism, thermogravimetric analyses were carried out on the $A X$ and $A X O$ samples before and after bentazone adsorption at open circuit (OC) conditions in the un-buffered solution. The desorption profiles of both samples are shown in Figure 8. The first peak at temperatures lower than $100{ }^{\circ} \mathrm{C}$, is assigned to the removal of physisorbed water. The peaks at temperatures higher than $400{ }^{\circ} \mathrm{C}$, which appear in the oxidized cloth before and after adsorption, are linked to the decomposition of the surface functionalities (Bandosz and Ania; 2006). The profiles of $A X_{\text {sat }}$ and $A X O_{\text {sat }}$ also show a new peak centered at around $280{ }^{\circ} \mathrm{C}$ which was not detected before the uptake, and thus it is assigned to the bentazone physisorbed in the porous texture of the carbon cloth. In the case of the oxidized carbon, $A X O_{\text {sat }}$, there is a small overlap of this peak with the one attributed to the decomposition of carboxylic groups, which is also present before bentazone adsorption. Nevertheless, after adsorption the intensity of the peak increases, due to the bentazone desorption. It is important to remark the absence of a second peak at higher temperatures, observed for instance in the case of other organic molecules (i.e., phenol) (Ania et al., 2005), which indicates a lack of specific interactions between the surface functionalities and the bentazone molecule. Therefore, this result demonstrates the proposed mechanism for the adsorption and electrosorption of bentazone, based exclusively on non-specific (dispersive) interactions between the aromatic ring of the adsorbate and the graphene layers of the carbon cloth, which would take place in the microporosity. Despite the molecule shows two well-delimited parts of different polarity (i.e., the aromatic ring and the functionalities), no specific interactions involving the functionalities are occurring. Consequently, it can be inferred that the adsorption rate of this herbicide is mainly controlled by the solution $\mathrm{pH}$ and it can be improved by polarization on carbon-based electrodes as discussed above. 
The relatively high temperature of the desorption peak (Figure 8) suggests that adsorption takes place mainly on surface active sites of high adsorption potential; this is in pores whose dimensions match those of the adsorbate (i.e, narrow micropores). It should be noted that this desorption peak appeared at almost the same temperature for both carbon samples, regardless of the amount of surface groups on the surface, suggesting that the same adsorption forces are involved in both cases. This is consistent with the similar textural properties of the carbon cloths.

Support for the role of narrow micropores in bentazone adsorption was provided by the analysis of the samples porosity after adsorption (Table 1). For this purpose, $\mathrm{N}_{2}$ and $\mathrm{CO}_{2}$ adsorption isotherms were recorded for the samples loaded with bentazone, after being washed with water to remove the excess of the adsorbate on the outer part of carbon, and dried at $120^{\circ} \mathrm{C}$. Before the experiments, the samples were outgassed at $120{ }^{\circ} \mathrm{C}$ under vacuum. The main difference as a result of bentazone adsorption is a decrease of the micropore volume. This effect is especially remarkable in the $A X$ sample which has the lower oxygen content. The same trend can be observed from the $\mathrm{CO}_{2}$ adsorption isotherms, underlining the important role of the narrow micropores in bentazone uptake. The highest decrease in $\mathrm{CO}_{2}$ uptake after adsorption corresponds to the non-modified sample $-A X$-, which is in good agreement with the largest adsorptive capacity achieved for this sample.

\section{Conclusions}

The adsorption/electrosorption of a common herbicide in aqueous solution by an activated carbon cloth was investigated and, based on the results, a mechanism of adsorption is proposed. The adsorption process depends on two important factors: the solution $\mathrm{pH}$ and the degree of functionalization of the carbon surface. Oxidation of carbon diminishes both 
the loading capacity and the adsorption rate of bentazone, while acidic solution $\mathrm{pH}$ seems to favor the uptake.

Two types of interactions are possible between the carbon cloth and bentazone: dispersive interactions between the aromatic ring and the $\pi$ electrons of the graphitic structure; an electrostatic attraction/repulsion when ions are present. The adsorbate ionization and the adsorbent's surface charges control the electrostatic interactions. The adsorption is drastically reduced when deprotonated acidic groups on the edges of the graphitic layers repel the bentazone anions. Furthermore, the surface groups control the adsorbent polarity which enables the competitive water adsorption, thus preventing dispersive interactions.

Applying an anodic polarization to the carbon cloth enhances the adsorption rate of bentazone. Moreover, this kind of experiment enables to better understand the adsorption process, and to clarify the role of $\mathrm{pH}$ in the overall process. Local $\mathrm{pH}$ changes occurring in the pores of the working carbon electrode during polarization seem to be critical for the enhancement of bentazone removal. Due to the high electrode potentials reached, protons are generated in the working electrode during polarization and the rate of adsorption is thereby enhanced. These results corroborate those obtained at open circuit conditions and enable to propose a mechanism of adsorption/electrosorption of bentazone on carbons through a main contribution of $\pi-\pi$ dispersive interactions.

\section{Acknowledgements}

The authors thank Actitex, France, for kindly supplying the activated carbon cloth. COA thanks MEC, Spain, for the financial support (EX2004-0612). Dr. Khomenko is also acknowledged for fruitful discussions. 


\section{References}

Afkhami, A. Conway, B.E. 2002. Investigation of Removal of Cr(VI), Mo(VI), W(VI), V(IV), and V(V) Oxy-ions from industrial waste-waters by adsorption and electrosorption at high-area carbon cloth. J. Colloid Interf. Sci., 251, 248-255.

Alfarra, A. Frackowiak, E. Béguin, F. 2002. Mechanism of lithium electrosorpion by activated carbons. Electrochim. Acta, 47, 545-1553.

Ania, C.O. Parra, J.B. Pevida, C. Arenillas, A. Rubiera, F. Pis, J.J. 2005. Pyrolysis of activated carbons exhausted with organic compounds. J. Anal. Appl. Pyrol., 74, 518524.

Ania, C.O. Parra, J.B. Pis, J.J. 2004. Oxygen-induced decrease in the equilibrium adsorptive capacities of activated carbons. Sci. Technol., 22, 337-351.

Ayranci, E. Conway, B.E. 2001. Removal of phenol, phenoxide and chlorophenols from waste-waters by adsorption and electrosorption at high-area carbon felt electrodes. J. Electroanal. Chem., 513, 100-110.

Ayranci, E. Hoda N., 2004. Adsorption of bentazone and propanil from aqueous solutions at the high area activated carbon cloth. Chemosphere, 57, 755-762.

Ban, A. Chafer, A. Wendt, H. 1998. Fundamentals of Electrosorption on activated carbon for waste water treatment of industrial effluents. J. Appl. Electrochem., 28, 227-236.

Bandosz, T.J. Ania, C.O. 2006. In Activated carbon surfaces for environmental remediation; Bandosz, T.J. Ed.; Elsevier Science and Technology, New York, Vol. 7, p 159. 
Boivin, A. Cherrier, R. Perrin-Ganier, C. Schiavon, M. 2004. Time effect of bentazone sorption and degradation in soil. Pest. Manag. Sci., 60, 809-814.

Boivin, A. Cherrier, R. Schiavon, M. 2005. A comparison of five pesticides adsorption and desorption processes in thirteen contrasting field soils. Chemosphere, 61, 668-676.

Brunauer. B. Deming L.S., Deming, W.E. Teller, E. 1940. On a theory of the van der Waals adsorption of gases. J. Am. Chem. Soc., 62, 1723-1732.

Derylo-Marczewska, A. Jaroniec, M. Gelbin, D. Seidel, A. 1984. Heterogeneity effects in single-solute adsorption from dilute solutions on solids. Chem. Scr., 24, 239-244.

Directive 2000/60/EC. EU water framework directive Official Journal of the European Union, L 327, on 22 December 2000.

Donnet, J.B. 1982. Structure and reactivity of carbons: from carbon black to carbon composites. Carbon, 20, 267-282.

Dousset, M. Babut, F. Andreux, Schiavon, M. 2004. Alachlor and bentazone losses from subsurface drainage of two soils. J. Environ. Qual., 33, 294-301.

Franz, M. Arafat, H. A., Pinto, N.G. 2000. Effect of chemical surface heterogeneity on the adsorption mechanism of dissolved aromatics on activated carbon. Carbon, 38, 18071819.

Giles, C., Mc Ewan, T., Nakhwa, S., Smith, D.J., 1960. Studies in adsorption. Part XI. A system of classification of solutions adsorption isotherms, and its use in diagnosis of adsorption mechanisms and in measurement of specific surface areas of solids. J. Chem. Soc., 3973.

Grey, T.L. Wehtje, G.R. Walker, R.H. Hajek, B.H. 1996. Sorption and mobility of bentazone in coastal plain soils. Weed Sci., 44, 166-170. 
Han, Y. Quan, X. Chen, S. Zhao, H. Cui, C. Zhao, Y. 2006a. Electrochemically enhanced adsorption of aniline on activated carbon fibers. Sep. Purif. Technol., 50, 365-372

Han, Y. Quan, X. Chen, S. Zhao, H. Cui, C. Zhao, Y. 2006b. Electrochemically enhanced adsorption of phenol on activated carbon fibers in basic aqueous solution. J. Colloid Interf. Sci., 299, 766-771.

Harry, I.D. Saha, B. Cumming, I.W. 2007. Surface properties of electrochemically oxidised viscose rayon based carbon fibres.Carbon, 45, 766-774.

Hinkebein, T.E. Price, M.K. 2005. Progress with the desalination and water purification technologies US roadmap. Desalination, 182, 19-28.

Karanfil, T. 2006. In Activated carbon surfaces for environmental remediation; Bandosz, T. J. Ed.; Elsevier Science and Technology, New York, Vol. 7, p 345.

Kinoshita, K. 1988. In Carbon: electrochemical and physicochemical properties. New York: John Wiley \& sons; p. 293.

Matlosz, M. Newman, J. 1986. Experimental investigation of a porous carbon electrode for the removal of mercury from contaminated brine. J. Electrochem. Soc., 133, 1850-1859.

Niu, J. Conway, B.E. 2002a. Development of techniques for purification of waste waters: removal of pyridine from aqueous solution by adsorption at high-area C-cloth electrodes using in situ optical spectrometry. J. Electroanal. Chem., 521, 16-28.

Niu, J. Conway, B.E. 2002b. Molecular structure factors in adsorptive removal of pyridinium cations, 1,4-pyrazine and 1-quinoline at high-area C-cloth electrodes for waste-water remediation. J. Electroanal. Chem., 529, 84-96.

Niu, J. Conway, B.E. 2002c. Adsorptive and electrosorptive removal of aniline and bipyridyls from waste-waters. J. Electroanal. Chem., 536, 83-92. 
Niu, J. Conway, B.E. 2003. Adsorption of organics onto an high-area C-cloth electrode from organic solvents and organic solvent/water mixtures. J. Electroanal. Chem., 546, $59-72$.

Noh, J.S. Schwarz, J.A. 1989. Estimation of the point of zero charge of simple oxides by mass titration. J. Colloid Interf. Sci., 130, 157-164.

Oren, Y. Soffer, A. 1983. Water desalting by means of electrochemical parametric pumping.1. The equilibrium properties of a batch unit-cell. J. Appl. Electrochem., 13, 473-487.

Park, S-J. Kim, Y-M. 2004. Influence of anodic treatment on heavy metal ion removal by activated carbon fibers J. Colloid Interf. Sci., 278, 276-281.

Peter, K. Volhardt, C. Schore, N.E. 1999. In Organic Chemistry: Structure and Function, WH Freeman Company, New York.

Pintar, A. 2005. Catalytic processes for the purification of drinking water and industrial effluents. Catalysis Today, 77, 451-465.

Ying, T. Y. Yang, K. L. Yiacoumi, S. Tsouris, C. 2002. Electrosorption of ions from aqueous solutions by nanostructured carbon aerogel. J. Colloid Interface Sci., 25018 27. 


\section{Figure 1.}

Molecular structure of bentazone, keto-enol tautomerism (Peter et al., 1999) and dissociation equilibrium.

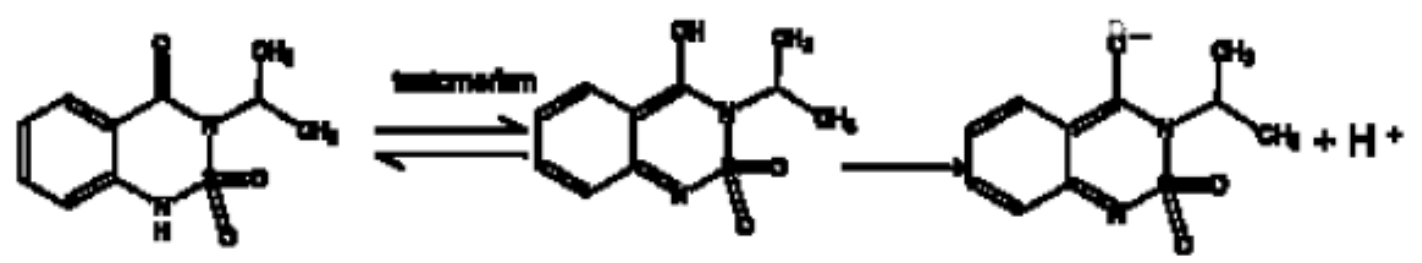




\section{Figure 2.}

Concentration decay curves of bentazone on the carbon cloths AX (solid symbols) and AXO (empty symbols) at different $\mathrm{pH}$ conditions. The initial concentration of pesticide (20 ppm) and the mass of carbon-cloth $(11.5 \mathrm{mg})$ were the same in all cases. The $\mathrm{pH}$ of the 0.01 mol. $L^{-1} \mathrm{Na}_{2} \mathrm{SO}_{4}$ supporting electrolyte solution is $\sim 5.5$. Symbols represent experimental data and the solid lines the fitting to the kinetics model.

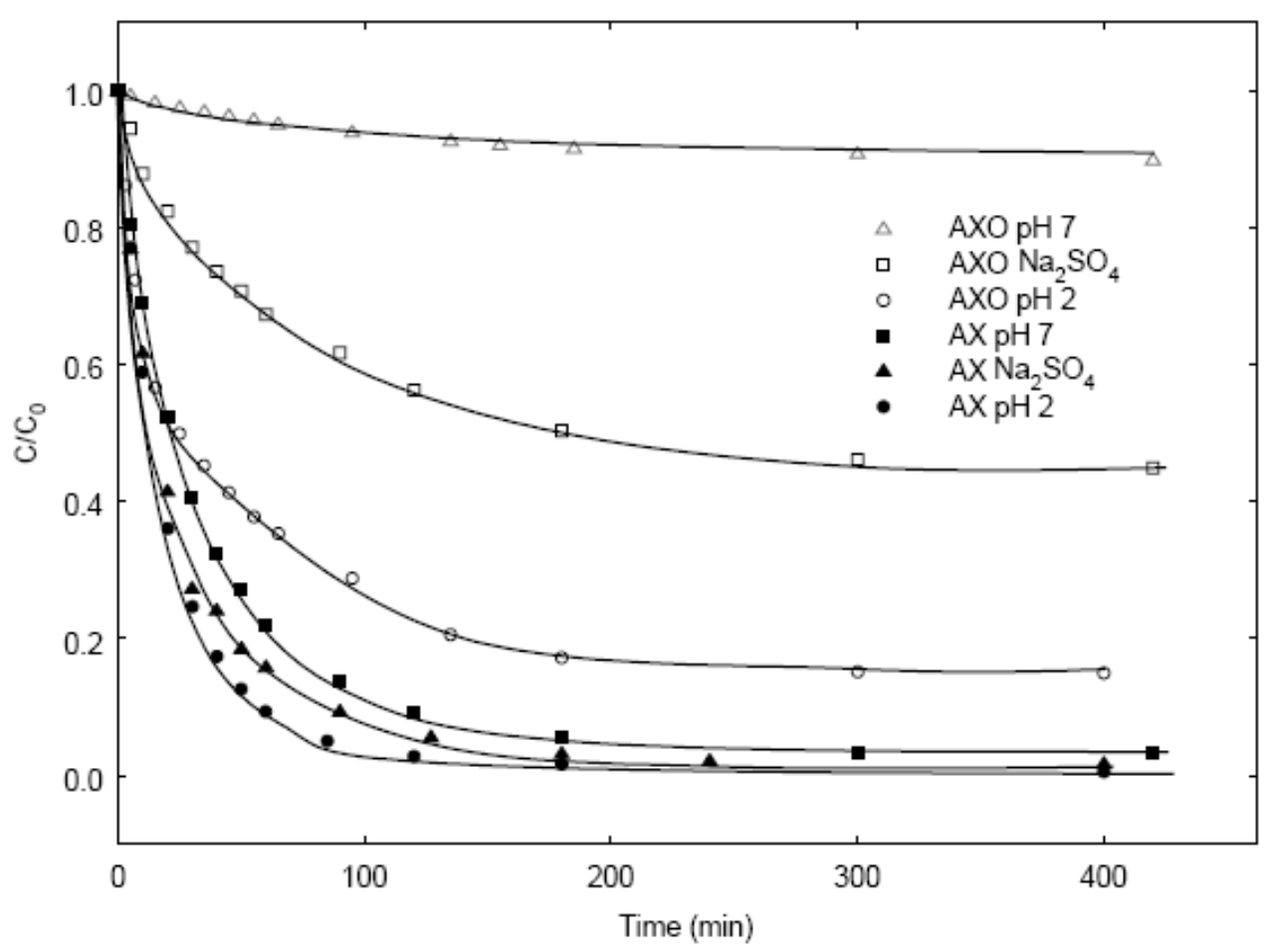




\section{Figure 3.}

Equilibrium adsorption isotherms of bentazone on the carbon cloths $\mathrm{AX}$ (solid symbols) and AXO (empty symbols) in $\mathrm{OC}$ at different values of solution $\mathrm{pH}$. The $\mathrm{pH}$ of the 0.01 mol. $L^{-1} \mathrm{Na}_{2} \mathrm{SO}_{4}$ supporting electrolyte solution is $\sim 5.5$. Symbols represent experimental data and the solid lines the fitting to the LF equation.

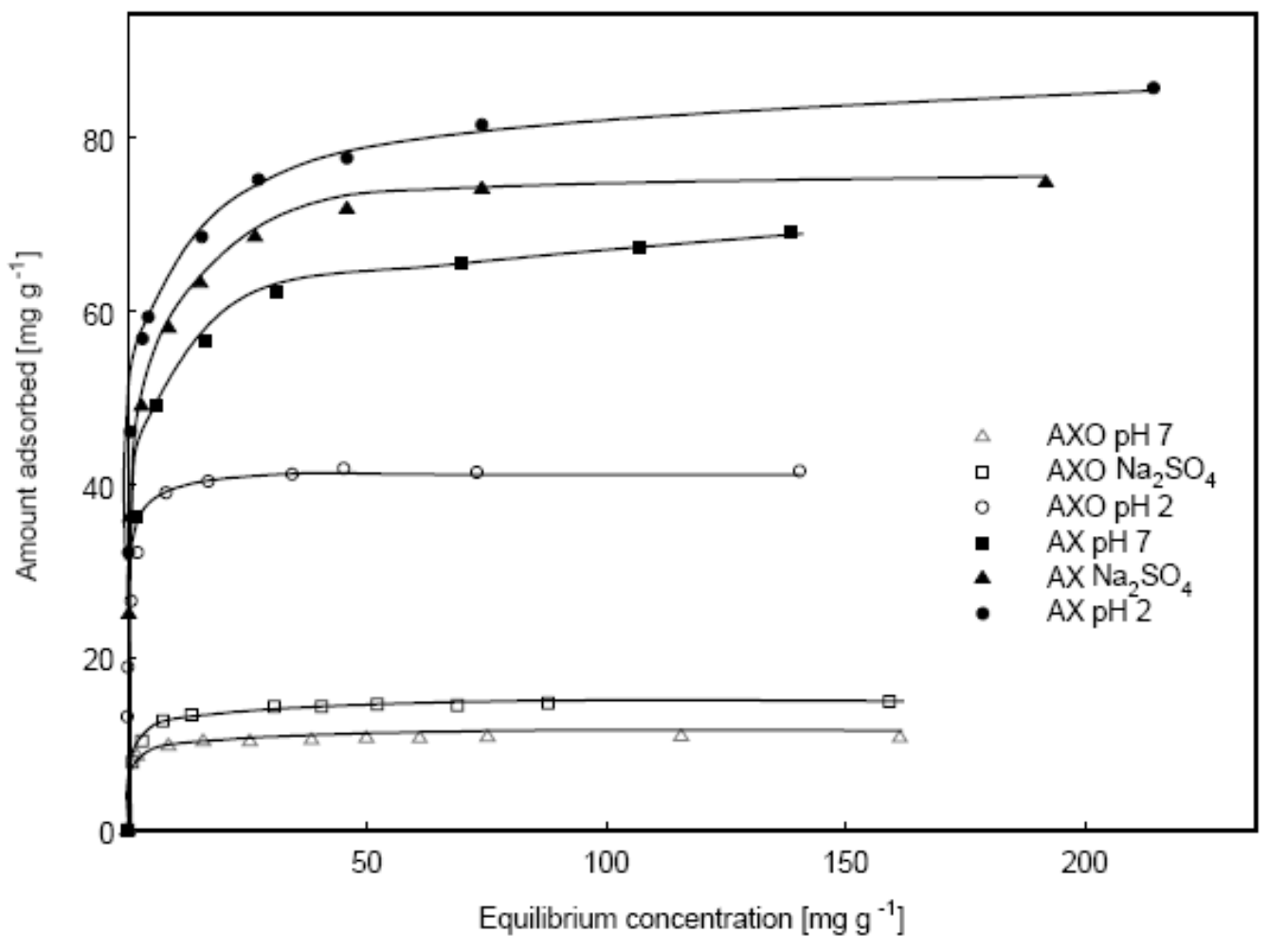




\section{Figure 4.}

Concentration decay curves of bentazone on the $A X O$ cloth under open-circuit (OC) and anodic galvanostatic polarization, in a non-buffered solution $\left(0.01 \mathrm{~mol} \cdot \mathrm{L}^{-1} \mathrm{Na}_{2} \mathrm{SO}_{4}\right.$ as supporting electrolyte). The initial concentration of pesticide (20 ppm) and the mass of carbon cloth $(11.5 \mathrm{mg})$ were the same in all cases. Symbols represent experimental data and the solid lines the fitting to the kinetics model.

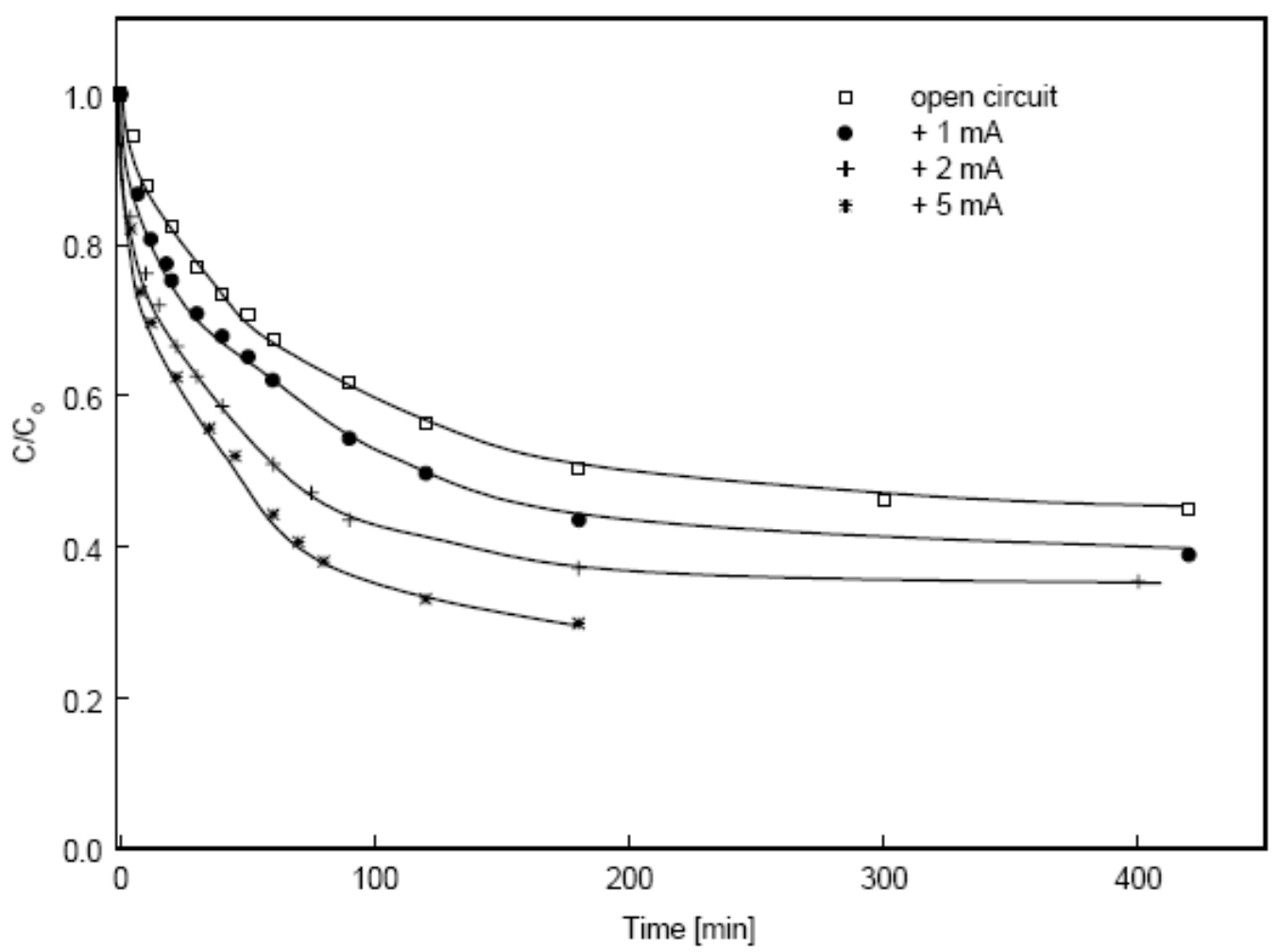




\section{Figure 5.}

Changes of working electrode potential upon anodic polarization at constant current using the $A X O$ sample as electrode.

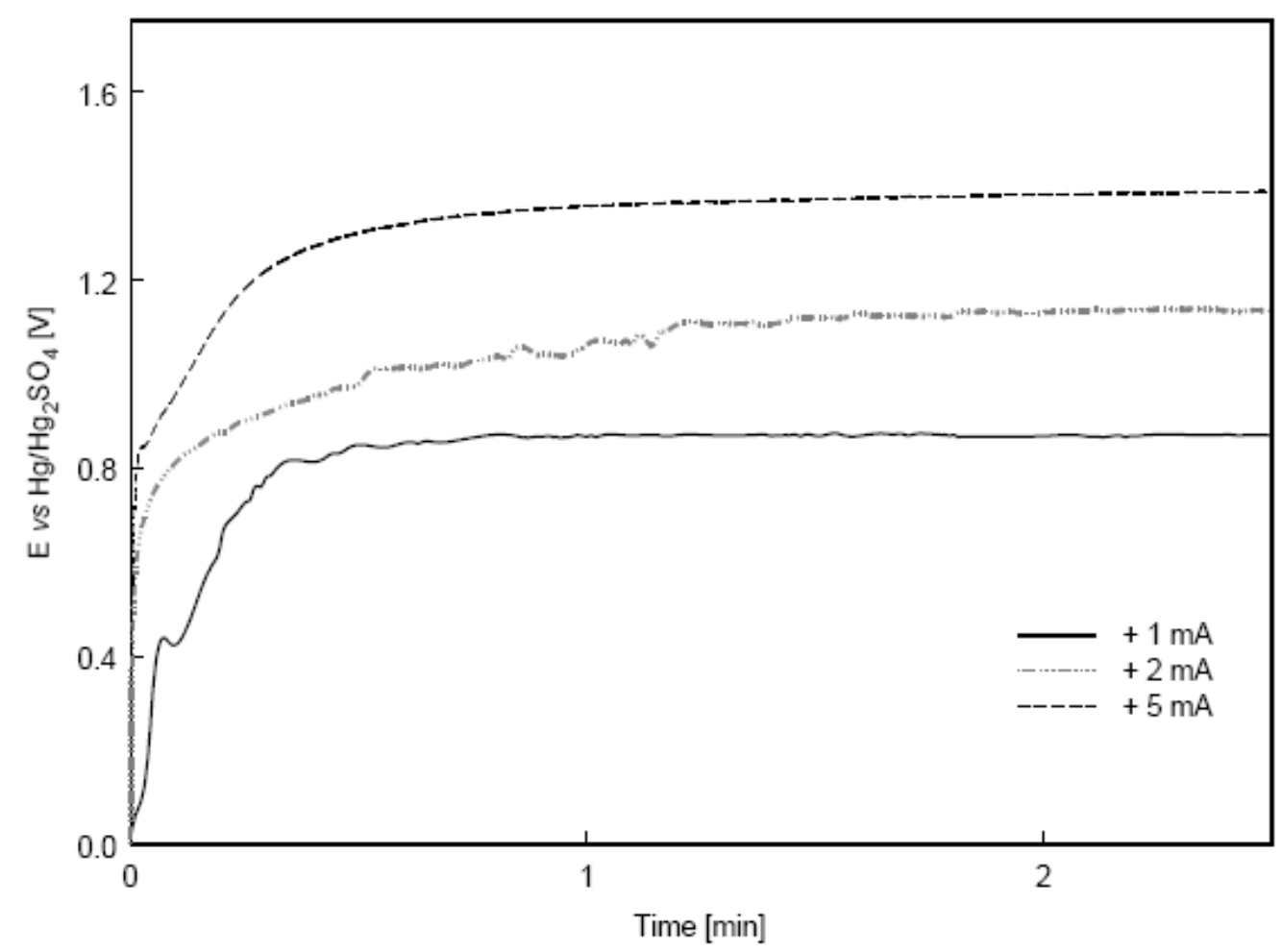




\section{Figure 6.}

Schematic representation of possible adsorption sites of bentazone on the carbon cloth under anodic polarization: A) through the aromatic ring; and B) ionic interaction through the negative charge on the bentazone molecule.
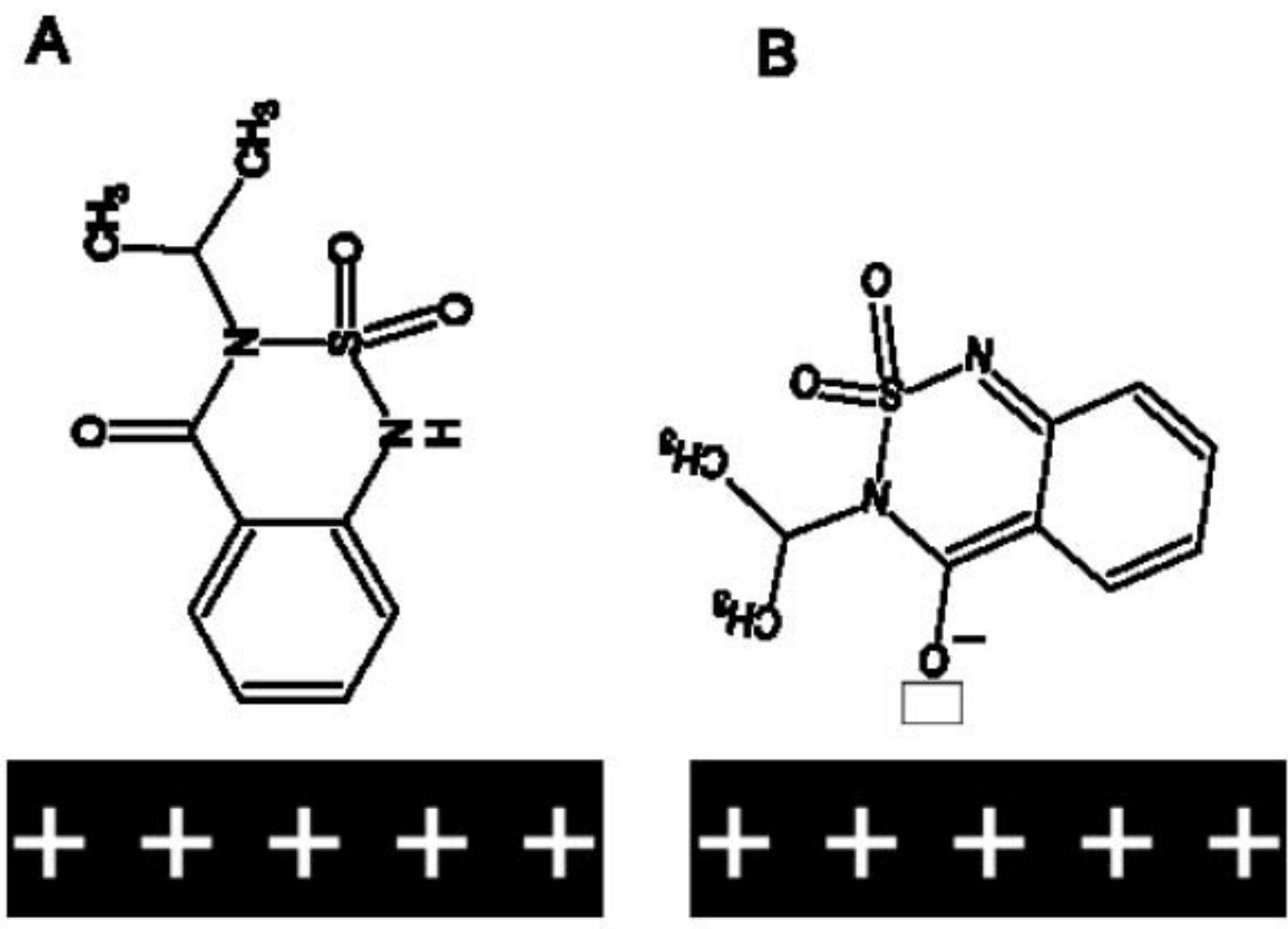


\section{Figure 7.}

Changes in the UV spectra of the bentazone solution while anodic polarization is being applied.

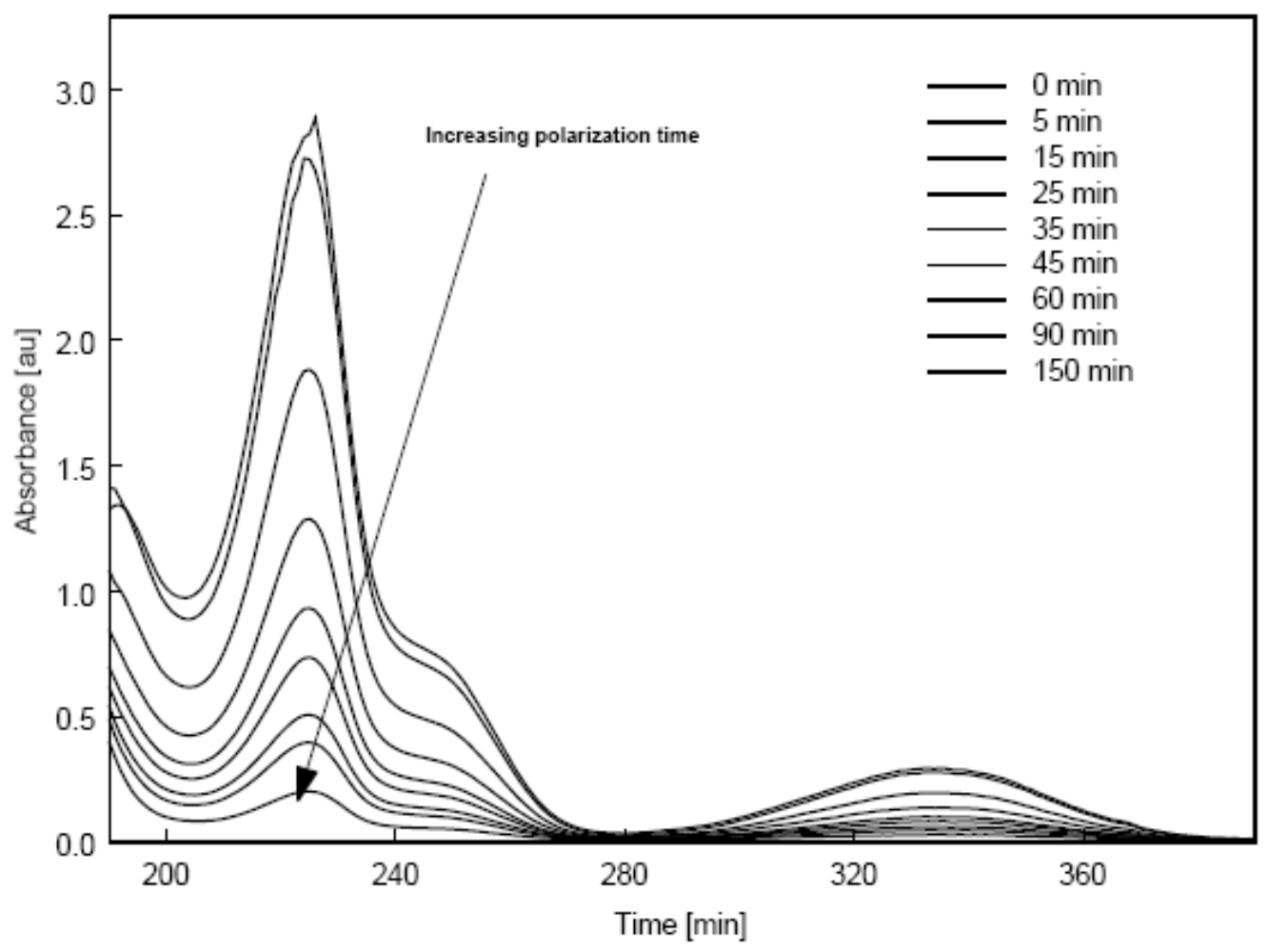


Figure 8.

Differential thermogravimetric analysis (DTG) under argon of the two carbon cloth samples before and after (sat) bentazone adsorption in open-circuit conditions.

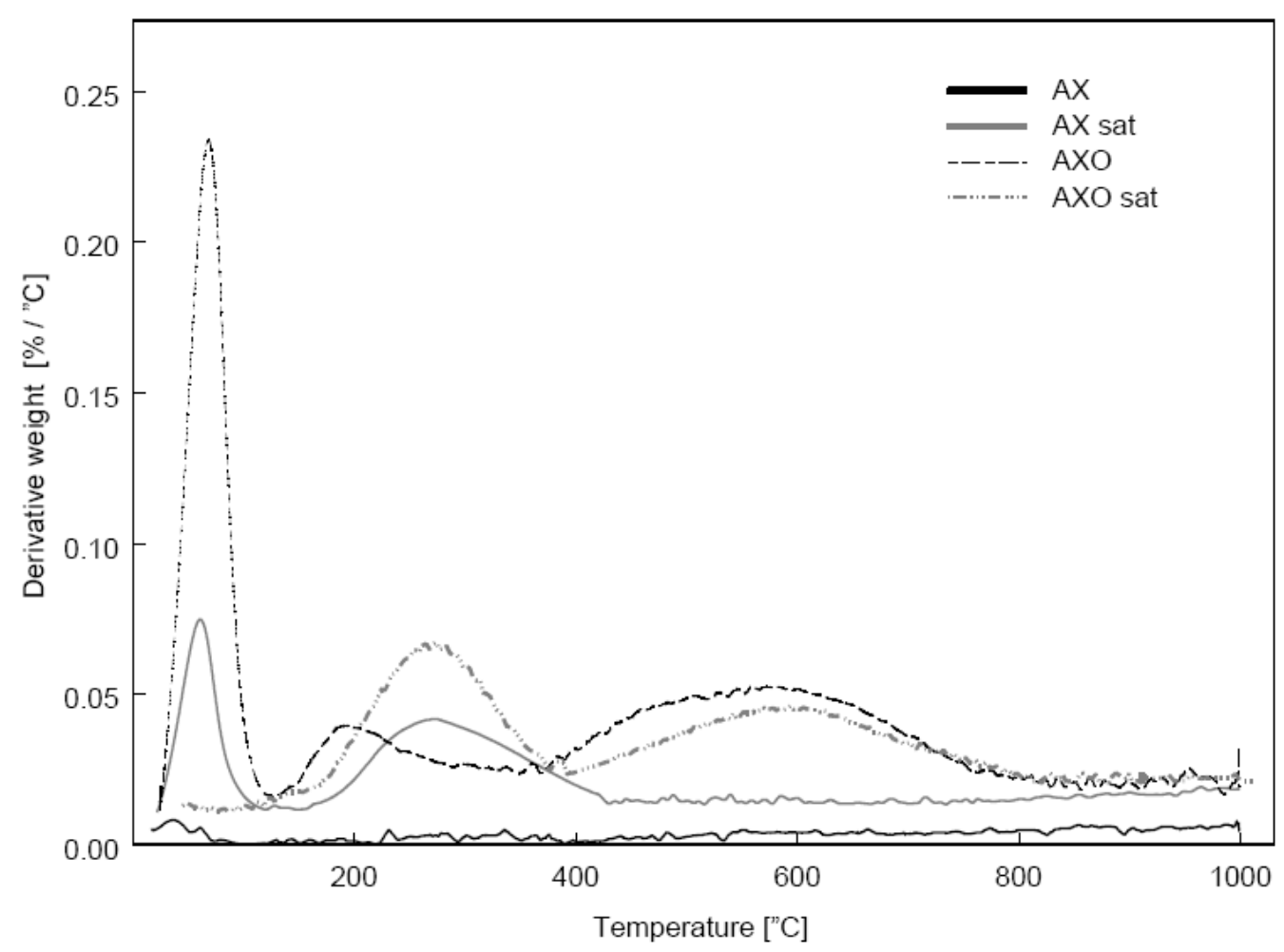


Table 1.

Textural and chemical characteristics of the studied cloths before and after (sat) bentazone adsorption.

\begin{tabular}{|c|c|c|c|c|c|}
\hline Sample & $\begin{array}{c}\mathrm{S}_{\mathrm{BET}} \\
{\left[\mathrm{m}^{2} \mathbf{g}^{-1}\right]}\end{array}$ & $\begin{array}{l}V_{\text {TOTAL }} \\
{\left[\mathrm{cm}^{3} \mathbf{g}^{-1}\right]}\end{array}$ & $\begin{array}{l}V_{\text {micropores }} \\
{\left[\mathrm{cm}^{3} \mathbf{g}^{-1}\right]^{\mathbf{a}}}\end{array}$ & $\begin{array}{l}V_{\text {mesopores }} \\
{\left[\mathrm{cm}^{3} \mathbf{g}^{-1}\right]^{\text {a }}}\end{array}$ & $\frac{\mathrm{V}_{\mathrm{CO}_{2}}}{\left[\mathrm{~cm}^{3} \mathrm{~g}^{-1}\right]^{b}}$ \\
\hline $\mathbf{A X}$ & 926 & 0.440 & 0.329 & 0.086 & 0.353 \\
\hline AXO & 960 & 0.482 & 0.331 & 0.127 & 0.345 \\
\hline AX sat & 690 & 0.298 & 0.247 & 0.031 & 0.286 \\
\hline \multirow[t]{3}{*}{ AXO sat } & 807 & 0.416 & 0.279 & 0.138 & 0.300 \\
\hline & & \multicolumn{4}{|c|}{ Surface functionalities from XPS data (at. \%) } \\
\hline & pH PZC & $\begin{array}{c}\text { O1s } \\
\text { (total) }\end{array}$ & $\begin{array}{c}\text { C1s C-O } \\
\text { phenol } \\
{[285.9 \mathrm{eV}]}\end{array}$ & $\begin{array}{c}\text { C1s C=O } \\
\text { quinone } \\
{[287.4 \mathrm{eV}]}\end{array}$ & $\begin{array}{l}\text { C1s COO- } \\
\text { carboxylic } \\
{[288.7 \mathrm{eV}]}\end{array}$ \\
\hline $\mathbf{A X}$ & 5.7 & 8.27 & 5.44 & 1.87 & - \\
\hline AXo & 2.5 & 19.17 & 6.84 & 3.92 & 4.14 \\
\hline
\end{tabular}




\section{Table 2.}

Adsorption/electrosorption parameters of first-order adsorption kinetics for bentazone at different values of solution $\mathrm{pH}$ ( $\mathrm{pH} \sim 5.5$ for $0.01 \mathrm{~mol}^{-\mathrm{L}^{-1}} \mathrm{Na}_{2} \mathrm{SO}_{4}$ )

\begin{tabular}{|c|c|c|c|c|}
\hline & & $\mathrm{q}_{\mathrm{e}}\left[\mathrm{mg} \mathrm{g}^{-1}\right]$ & $K_{\text {ads }} \times 10^{3}\left[\mathrm{~min}^{-1}\right]$ & $\mathbf{r}^{2}$ \\
\hline \multicolumn{5}{|c|}{ OPEN CIRCUIT (OC) } \\
\hline \multirow{2}{*}{ pH 2} & $\mathbf{A X}$ & 27.7 & 37.64 & 0.9954 \\
\hline & AXO & 22.8 & 18.30 & 0.9931 \\
\hline $\mathrm{Na}_{2} \mathrm{SO}_{4}$ & $\mathbf{A X}$ & 27.4 & 22.54 & 0.9944 \\
\hline $0.01 \mathrm{M}$ & AXO & 16.5 & 12.37 & 0.9979 \\
\hline \multirow{2}{*}{ pH 7} & $\mathbf{A X}$ & 26.3 & 20.64 & 0.9946 \\
\hline & AXO & 3.4 & 9.54 & 0.9992 \\
\hline \multicolumn{5}{|c|}{ ANODIC POLARIZATION in $0.01 \mathrm{~mol}^{-1} \mathrm{Na}_{2} \mathrm{SO}_{4}$} \\
\hline $\mathrm{OC}$ & AXO & 16.5 & 12.37 & 0.9979 \\
\hline$+1 \mathbf{m A}$ & AXO & 17.2 & 13.37 & 0.9914 \\
\hline$+2 \mathbf{m A}$ & AXO & 17.7 & 19.99 & 0.9880 \\
\hline$+5 \mathrm{~mA}$ & $\mathrm{AXO}$ & 19.3 & 24.30 & 0.9904 \\
\hline
\end{tabular}




\section{Table 3.}

Langmuir-Freundlich isotherm parameters for bentazone removal at different $\mathrm{pH}$ values (pH 5.5 for 0.01 mol.L $\mathrm{L}^{-1} \mathrm{Na}_{2} \mathrm{SO}_{4}$ )

\begin{tabular}{llcccc}
\hline & & $\begin{array}{c}\mathbf{q}_{0} \\
{\left[\mathbf{m g ~ g}^{-1}\right]}\end{array}$ & $\mathbf{n}$ & $\mathbf{K}$ & $\mathbf{r}^{\mathbf{2}}$ \\
\hline \multirow{2}{*}{$\mathbf{p H ~ 2}$} & AX & 127 & 0.36 & 0.49 & 0.984 \\
& AXO & 57 & 0.32 & 1.83 & 0.986 \\
\hline $\mathrm{Na}_{2} \mathrm{SO}_{4}$ & AX & 115 & 0.37 & 0.44 & 0.996 \\
$\mathbf{0 . 0 1 M}$ & AXO & 17 & 0.96 & 0.36 & 0.997 \\
\hline \multirow{2}{*}{$\mathbf{p H ~} 7$} & AX & 80 & 0.77 & 0.57 & 0.996 \\
& AXO & 13 & 0.80 & 0.48 & 0.990 \\
\hline
\end{tabular}

